to expectation, he was stronger and had less diarrhoea. From this time, at first slowly, afterwards more rapidly, he improved without relapse, having been rescued from his desperate strait only by the native vigor of his constitution. The granulating surface on his back was dressed with charpie and myrrh; he was out of bed on November 8th. and was discharged, well, November 23d.

Incised Wound of the Knee, with Section of the Ligamentum Patella.June 23, 1876. M. G., aged thirty years, while mowing, cut his leg with a scythe, and was brought to the hospital four hours afterwards. $\mathrm{He}$ had received an incised wound two and a half inches long, on the front of the left leg just below the knee. The cut was transverse to the long axis of the limb, and the ligamentum patella had been completely severed just above its insertion into the tubercle of the tibia. At the time it was impossible to ascertain whether the knee-joint was involved without an examination of the wound, inquisitive rather than necessary or advisable. The cut edges of the ligamentum patellæ were brought together with three sutures of carbolized strands of Chinese silk, and one vessel was tied with a ligature of the same material. All the ends of both sutures and ligature were cut short. The wound was then washed out with an aqueous solution of carbolic acid, one part to forty, and its cutaneous edges were united with sutures of carbolized silk. The leg was placed on a ham splint, and the wound was dressed with cotton batting kept saturated with an aqueous solution of carbolic acid, one part to eighty. Ice-bags were applied to the knee. On the 27 th all the sutures were removed, and by June 29th there was good and perfect union of the edges of the wound. The patient suffered but very little pain, and there was but a slight and temporary swelling in the immediate vicinity of the wound. The cotton-batting dressing and ice-bags were kept applied for one or two days longer, and from motives of prudence the man was kept in bed with a splint on until August 3d. The splint was then removed, and the function of the ligamentum patellæ was unimpaired. Discharged August 7th.

\title{
THE TREATMENT OF CHANCROIDS.
}

Messrs. Editors, - Dr. Greenough's article, in your number for January 11th, suggests comment. If Dr. Greenough's experience is the average for your locality, the Boston chancroid is certainly a milder affair than the affection as we see it here. In hospital practice phagedenic chancroids with extensive destruction of the prepuce are by no means uncommon; loss of the entire glans is less frequent, but cannot be considered a curiosity, and destruction of the major part of the corpora cavernosa, and even of the entire penis, I have seen on several occasions. The use of iodoform as described by Dr. Greenough has been the common practice at the Charity Hospital for several years, in some cases preceded by nitric acid, but usually not. In $187 j$, three hundred and seventy-six cases were under treatment, and the average period of cure was about thirty days, which certainly does not equal the brilliant results recorded by Dr. Greenough. This further leads me to believe that our average hospital chancroids are severer lesions than those met with in your city, un- 
less Dr. Greenough's were mainly perambulating cases. I admit the thorough inefficiency of nitrate of silver in these cases, and do not think that nitric acid is very much better. I therefore replace them with a stronger caustic, the nitrate of zinc (vide New Remedies, March, 1876) or one still stronger, the actual cautery. This latter must be used at a white heat or not at all. Red heat will do more harm than good; it simply causes a burn, with a slowly separating slough, flabby granulations, tardy healing, and a retractile cicatrix. The results obtained by the actual cautery have been detailed elsewhere (Arch. of Clin. Surg., Nov., 1876). An anæsthetic is rarely necessary, but when it is demanded I employ nitrous oxide (in private practice), usually administering it myself. The disagreeable odor of idoform may be obviated in great measure by using a saturated ethereal solution, which appears to be fully as efficient as the powder. It is also admirable as an injection in cases of subpreputial chancroid complicated with phymosis. The solution should be thoroughly protected from the light. Respectfully yours, Henry G. Piffard, M.D.,

NEw YoRx, June 13, 1877. Surgeon to Charity Hospital, etc.

COMPARATIVE MORTALITY-RATES FOR THE WEEK ENDING JANUARY 13, 1877.

\begin{tabular}{|c|c|c|c|c|}
\hline & $\begin{array}{l}\text { Estimated Population, } \\
\text { July 1, 1877. }\end{array}$ & $\begin{array}{l}\text { Total Mortality } \\
\text { for the Week. }\end{array}$ & $\begin{array}{l}\text { Annual Death-Rate } \\
\text { per } 1000 \text { for the Week. }\end{array}$ & $\begin{array}{l}\text { Death-Rate for the } \\
\text { Year 18i6. }\end{array}$ \\
\hline New York & $1,077,228$ & 459 & 22.16 & 27.46 \\
\hline Philadelphia & 850,856 & & & 22.24 \\
\hline Brooklyn & วั27,830 & 189 & 18.62 & 24.31 \\
\hline Chicago . & 420,000 & 173 & 21.40 & 2041 \\
\hline Boston . & 363,940 & 128 & 18.01 & 2339 \\
\hline Providence & 103,000 & 34 & 17.16 & 18.34 \\
\hline Worcester & 52,977 & 19 & 18.65 & 22.00 \\
\hline Lowell . & 53,678 & 26 & 25.18 & 2221 \\
\hline Cambridge & 51,572 & 17 & 17.14 & 2054 \\
\hline Fall River & 50,370 & 13 & 13.42 & 22.04 \\
\hline Lawrence & 37,626 & 17 & 23.49 & 23.32 \\
\hline Lynn . & 33,524 & 10 & 15.51 & 21.37 \\
\hline Springfield & 32,976 & 9 & 14.19 & 19.69 \\
\hline Salem . & 26,739 & 15 & 29.17 & 23.57 \\
\hline
\end{tabular}

Normal Death-Rate, 17 per 1000.

\section{DR. GERRY'S CASE OF IN'TUSSUSCEPTION.}

Messrs. Edirors, - I notice in your reports, in to-day's Joursal, of the above very interesting and important case, that Dr. Bowditch is quoted as having said that " in his opinion the patient did well in spite of the treatment, not owing to it." As the treatment from June 29th to July 15th (including, beyond all doubt, the entire period in which the intestine would be in peril from improper treatment) was dictated by myself in consultation, and was, I am convinced, the means, humanly speaking, of saving the patient's life, I may be permitted to reply to this somewhat trenchant criticism. The patient had, before calling either Dr. Gerry or myself, taken large doses of a purgative, peculiarly stimulative, of peri- 